\title{
Tick-borne zoonotic pathogens in birds in Guangxi, Southwest China
}

\author{
Jifei Yang', Zhijie Liu', Qingli Niu', Zhancheng Tian', Junlong Liu', Guiquan Guan', Guangyuan Liu', Jianxun Luo', \\ Xiaolong Wang ${ }^{1,3^{*}}$ and Hong Yin ${ }^{1,2^{*}}$
}

\begin{abstract}
Background: Wildlife is an important natural reservoir of many tick-borne pathogens. These agents have an impact on the health of humans and other animals throughout the world. This study was conducted to determine whether and what species of tick-borne agents had infected wild birds collected from Guangxi, in southwest China.

Findings: Liver samples obtained from wild birds were tested for the presence of tick-borne pathogens by PCR assays and sequencing of the flagellin and 16S rRNA genes. Borrelia garinii was detected in Eurasian collared doves $(2 / 57,3.5 \%)$ from among the 95 wild birds. Anaplasma phagocytophilum was detected in Eurasian collared doves $(2 / 57,3.5 \%)$ and Eurasian eagle owls (2/13, $15.4 \%)$. Ehrlichia chaffeensis and a potential novel Anaplasma sp. were identified in Common pheasant (1/12, $8.3 \%)$. These results suggest the involvement of birds in the cycle of tick-borne diseases. To our knowledge, this is the first study to document infection of birds with B. garinii, A. phagocytophilum, E. chaffeensis and the novel Anaplasma sp. in China.

Conclusions: Tick-borne zoonotic bacteria B. garinii, A. phagocytophilum and E. chaffeensis, and a potential novel Anaplasma sp., were identified in wild birds in southwest China. The presence of these agents in birds increases the potential spread over long distances and the risk of transmission of infection from birds to new hosts, including humans.
\end{abstract}

Keywords: Borrelia garinii, Anaplasma phagocytophilum, Ehrlichia chaffeensis, Bird, Tick-borne disease, Zoonosis, China

\section{Background}

The transmission of infectious diseases between wild animals and humans is an issue of public interest [1]. It was reported that $71.8 \%$ of human emerging infectious diseases (EIDs) identified between 1940 and 2004 originated from wildlife, and vector-borne diseases are believed to have been responsible for almost $30 \%$ of EID events in the last few years [2].

Ticks can serve as vectors for a variety of pathogens, which are maintained in nature through an enzootic cycle between vector ticks and vertebrate hosts, primarily wild animals [3, 4]. Some of these agents, such as Anaplasma phagocytophilum and Ehrlichia chaffeensis,

\footnotetext{
* Correspondence: yttuhh@yeah.net; yinhong@caas.cn

'State Key Laboratory of Veterinary Etiological Biology, Key Laboratory of Veterinary Parasitology of Gansu Province, Lanzhou Veterinary Research Institute, Chinese Academy of Agricultural Science, Xujiaping 1, Lanzhou, Gansu 730046, P. R. China

Full list of author information is available at the end of the article
}

are now recognized as important emerging or reemerging pathogens with serious public health implications $[5,6]$. Growing evidence suggests that wild birds can alter the distribution of vectors and pathogens through their movement, and increase the infectious disease risk to wild and domestic animals as well as human beings $[3,7]$. Therefore, it is important to identify wild birds that serve as major reservoirs of those agents. The purpose of this study was to determine the potential occurrence of Borrelia burgdorferi sensu lato, A. phagocytophilum, and E. chaffeensis in wild birds collected from Guangxi province, in southwest China.

\section{Methods}

Wild birds that had died as a result of accidental injury were cryopreserved at the Guilin Wildlife Rescue Center in Guangxi Province, southwest China. Ninety-five birds were collected from March 2010 to April 2012 and identified as belonging to nine species: fifty-seven Eurasian 
collared doves (Streptopelia decaocto), eight Spotbills (Anas poecilorhyncha), twelve Common pheasants (Phasianus colchicus), thirteen Eurasian eagle owls (Bubo bubo), one Golden pheasant (Chrysolophus pictus), one Japanese wood pigeon (Columba janthina), one White-billed crow (Corvus woodford), one Chukar partridge (Alectoris chukar), and one Grey heron (Ardea cinerea). Liver samples were collected and preserved at $-20{ }^{\circ} \mathrm{C}$ until use.

Total DNA was extracted from the 95 frozen liver samples using a Gentra Puregene DNA purification kit (Qiagen, Beijing, China) according to the protocols provided. All DNA samples were examined for the presence of B. burgdorferi s.l., A. phagocytophilum and E. chaffeensis by nested PCRs [4, 8-10]. Genomic DNA extracted from experimental sheep infected with A.phagocytophilum (Gene accession No. JN558811) and B. garinii strain PBi (American Type Culture Collection), and a plasmid containing the 16S rRNA gene of E. chaffeensis were used as positive controls; sterile water was used as the blank control. The amplification products were purified, cloned and subjected to sequencing (Sangon, Shanghai, China), and the nucleotide sequences obtained were compared with the published sequences in GenBank by a BLAST search.

The animal experiments complied with the Ethical Guidelines and were approved by our Institutional Ethics Committee.

\section{Results and discussion}

The GenBank accession numbers for the partial 16S rRNA gene sequences obtained in this study were: KC916730 and KC916731 for A. phagocytophilum; KT596734-KT596736 for E. chaffeensis; and KT596739 and KT596740 for the unclassified Anaplasma sp. The partial flagellin gene sequences of B. burgdorferi s.l. were assigned accession numbers KT596741 and KT596742.

Of the 95 wild birds, two tested positive for B. burgdorferi s.l. (Eurasian collared dove, 2/57, $3.5 \%$ ). The flagellin gene sequences (377 bp) of B.burgdorferi s.l. obtained from Eurasian collared doves (GenBank accession no. KT596741 and KT596742) were $99.7 \%$ identical. Sequence analysis revealed that the strains were most closely related to the Borrelia garinii genospecies (GenBank accession no. AB001716), with 99.7 to $100 \%$ identity.

Infection with $A$. phagocytophilum was detected in two Eurasian collared doves $(2 / 57,3.5 \%)$ and two Eurasian eagle owls $(2 / 13,15.4 \%)$. The 16S rRNA gene sequences (641 bp) of A. phagocytophilum amplified from Eurasian collared doves (GenBank accession no. KC916730) and Eurasian eagle owls (GenBank accession no. KC916731) were $100 \%$ identical to the sequences detected in deer and cattle from Japan (GenBank accession no. LC060987 and EU368728).
One liver sample collected from a Common pheasant (1/12, $8.3 \%)$ was positive for E. chaffeensis. The partial 16S rRNA gene sequences (477 bp) of E. chaffeensis (GenBank accession no. KT596734-KT596736) were $99.0 \%$ identical to those of strain Arkansas (GenBank accession no. NR_074500) and strains from ticks found in Southern China (GenBank accession no. AF147752). In addition, two sequences obtained from Common pheasant (GenBank accession no. KT596739 and KT596740) showed 99.8 \% identity to the unclassified Anaplasma strains HLAE344 (GenBank accession no. GU075704) and BJ01 (GenBank accession no. JN715833) derived from Haemaphysalis longicornis ticks, suggesting a potential novel Anaplasma sp. in the Common pheasant.

These data revealed that four species of wild bird were positive for three tick-borne zoonotic pathogens: $B$. garinii was identified in Eurasian collared doves; $A$. phagocytophilum was identified in Eurasian collared doves and Eurasian eagle owls; E. chaffeensis and the potential novel Anaplasma sp. were identified in Common pheasants. No other bird species was positive for the pathogens investigated in this study.

To date, five genospecies (B. burgdorferi sensu stricto, B. garinii, B. afzelii, B. sinica and B. valaisiana) of $B$. burgdorferi s.l. have been identified in China [11, 12]. Among them, B. garinii is the genospecies most frequently isolated and is distributed mainly in northern China [12]. In the present study, we report for the first time the presence of $B$. garinii in birds in southwest China. Birds have been implicated as reservoirs for B. garinii and B. valaisiana through detection of these pathogens in ticks feeding on birds [7, 13-15]. Therefore, the occurrence of B. garinii in Eurasian collared doves is not surprising.

Seven species of Ehrlichia and Anaplasma (E. chaffeensis, E.canis, A.phagocytophilum, A.ovis, A.marginale, A. centrale, and A.platys) have been reported in China [16-19]. Among them, A.phagocytophilum and E.chaffeensis have been identified in ticks, rodents, deer, domestic animals and humans [19-22]. In this study, $A$. phagocytophilum and E.chaffeensis were identified for the first time in birds. Previous studies have shown low rates of infection with A.phagocytophilum and $E$. chaffeensis in ticks feeding on birds [7, 23]. This could be the reason for the low prevalence of these agents in birds in this study. Moreover, a potential novel Anaplasma sp. was identified in birds, which was distinct from all known Anaplasma species.

In summary, tick-borne zoonotic bacteria B. garinii, $A$. phagocytophilum and E.chaffeensis, and a potential novel Anaplasma sp., were identified in birds in this study. These results suggest the potential involvement of birds in the cycle of tick-borne diseases in southwest China. However, the role of these bird species as reservoir hosts for the agents identified should be further investigated. 


\section{Conclusions}

To our knowledge, this is the first study to document infection of birds with B. garinii, A. phagocytophilum, E. chaffeensis and the novel Anaplasma sp. in China. The presence of these agents indicates the possible role of birds in the dispersal of ticks and their associated infectious agents over large distances, and suitable vectors may allow the transmission of infection from birds to new hosts, including humans.

\section{Competing interests}

The authors declare that they have no competing interests.

\section{Authors' contributions}

$H Y$ and JY designed this study and critically revised the manuscript. XW participated in its design, coordination and manuscript revision. JY, ZL and GG participated in sample collection. JY, QN, GL and JL performed the experiments, data analysis, and drafted the manuscript. All the authors read and approved the final manuscript.

\section{Acknowledgements}

This study was financially supported by the NSFC (№31372432, №31201899, №31272556, №31402189, №31471967), ASTIP, FRIP (2014ZL010), CAAS; Creative Research Groups of Gansu Province (№1210RJIA006); NBCIS CARS-38, Special Fund for Agro-scientific Research in the Public Research (№201303035, №201303037), MOA; 973 Program (2015CB150300), Supporting Program (2013BAD12B03, 2013BAD12B05), MOST, China; Jiangsu Co-innovation Center programme for Prevention and Control of Important Animal Infectious Diseases and Zoonoses, State Key Laboratory of Veterinary Etiological Biology Project. The research was also facilitated by CRP No. 16198/RO IAEA

\section{Author details}

State Key Laboratory of Veterinary Etiological Biology, Key Laboratory of Veterinary Parasitology of Gansu Province, Lanzhou Veterinary Research Institute, Chinese Academy of Agricultural Science, Xujiaping 1, Lanzhou, Gansu 730046, P. R. China. ${ }^{2}$ Jiangsu Co-innovation Center for Prevention and Control of Important Animal Infectious Diseases and Zoonoses, Yangzhou 225009, P. R. China. ${ }^{3}$ Center of Conservation Medicine \& Ecological Safety, Northeast Forestry University, Harbin, Heilongjiang 150040, P. R. China.

Received: 22 September 2015 Accepted: 4 December 2015

Published online: 15 December 2015

\section{References}

1. Martin C, Pastoret PP, Brochier B, Humblet MF, Saegerman C. A survey of the transmission of infectious diseases/infections between wild and domestic ungulates in Europe. Vet Res. 2011;42:70.

2. Jones KE, Patel NG, Levy MA, Storeygard A, Balk D, Gittleman JL, et al. Global trends in emerging infectious diseases. Nature. 2008;451(7181):990-3.

3. Hamer SA, Goldberg TL, Kitron UD, Brawn JD, Anderson TK, Loss SR, et al. Wild birds and urban ecology of ticks and tick-borne pathogens, Chicago, Illinois, USA, 2005-2010. Emerg Infect Dis. 2012;18(10):1589-95.

4. Kawahara M, Rikihisa Y, Lin Q, Isogai E, Tahara K, Itagaki A, et al. Novel genetic variants of Anaplasma phagocytophilum, Anaplasma bovis, Anaplasma centrale, and a novel Ehrlichia sp. in wild deer and ticks on two major islands in Japan. Appl Environ Microbiol. 2006;72(2):1102-9.

5. Chen SM, Dumler JS, Feng HM, Walker DH. Identification of the antigenic constituents of Ehrlichia chaffeensis. Am J Trop Med Hyg. 1994;50(1):52-8.

6. Woldehiwet Z. The natural history of Anaplasma phagocytophilum. Vet Parasitol. 2010;167(2-4):108-22.

7. Lommano E, Dvorak C, Vallotton L, Jenni L, Gern L. Tick-borne pathogens in ticks collected from breeding and migratory birds in Switzerland. Ticks Tick Borne Dis. 2014;5(6):871-82.

8. Yang J, Liu Z, Guan G, Che R, Niu Q, Li Y, et al. Evaluation of molecular methods for detection of Borrelia burgdorferi senso lato in ticks. Diagn Microbiol Infect Dis. 2012;73(1):80-3.

9. Wallich R, Helmes C, Schaible UE, Lobet Y, Moter SE, Kramer MD, et al. Evaluation of genetic divergence among Borrelia burgdorferi isolates by use of OspA, fla, HSP60, and HSP70 gene probes. Infect Immun. 1992;60(11):4856-66.
10. Barlough JE, Madigan JE, DeRock E, Bigornia L. Nested polymerase chain reaction for detection of Ehrlichia equi genomic DNA in horses and ticks (Ixodes pacificus). Vet Parasitol. 1996;63(3-4):319-29.

11. Masuzawa T, Takada N, Kudeken M, Fukui T, Yano Y, Ishiguro F, et al. Borrelia sinica sp. nov., a lyme disease-related Borrelia species isolated in China. Int J Syst Evol Microbiol. 2001;51(Pt 5):1817-24.

12. Hao Q, Hou X, Geng Z, Wan K. Distribution of Borrelia burgdorferi sensu lato in China. J Clin Microbiol. 2011;49(2):647-50.

13. Humair PF, Postic D, Wallich R, Gern L. An avian reservoir (Turdus merula) of the Lyme borreliosis spirochetes. Zentralbl Bakteriol. 1998;287(4):521-38.

14. Kurtenbach K, Peacey M, Rijpkema SG, Hoodless AN, Nuttall PA, Randolph SE. Differential transmission of the genospecies of Borrelia burgdorferi sensu lato by game birds and small rodents in England. Appl Environ Microbiol. 1998;64(4):1169-74.

15. Taragel'ova V, Koci J, Hanincova K, Kurtenbach K, Derdakova M, Ogden NH, et al. Blackbirds and song thrushes constitute a key reservoir of Borrelia garinii, the causative agent of borreliosis in Central Europe. Appl Environ Microbiol. 2008;74(4):1289-93.

16. Xia Z, Yu D, Mao J, Zhang Z, Yu J. The occurrence of Dirofilaria immitis, Borrelia burgdorferi, Ehrlichia canis and Anaplasma phagocytophium in dogs in China. J Helminthol. 2012;86(2):185-9.

17. Wen B, Cao W, Pan H. Ehrlichiae and ehrlichial diseases in China. Ann N Y Acad Sci. 2003;990:45-53.

18. Cao WC, Zhao QM, Zhang PH, Dumler JS, Zhang XT, Fang LQ, et al. Granulocytic Ehrlichiae in Ixodes persulcatus ticks from an area in China where Lyme disease is endemic. J Clin Microbiol. 2000;38(11):4208-10.

19. Yang J, Li Y, Liu Z, Liu J, Niu Q, Ren Q, et al. Molecular detection and characterization of Anaplasma spp. in sheep and cattle from Xinjiang, northwest China. Parasit Vectors. 2015:8:108.

20. Dong T, Qu Z, Zhang L. Detection of A. phagocytophilum and E. chaffeensis in patient and mouse blood and ticks by a duplex real-time PCR assay. PLoS One. 2013;8(9):e74796.

21. Li Y, Chen Z, Liu Z, Liu J, Yang J, Li Q, et al. Molecular survey of Anaplasma and Ehrlichia of red Deer and Sika Deer in Gansu, China in 2013. Transbound Emerg Dis. 2015. doi:10.1111/tbed.12335.

22. Zhang XC, Zhang LX, Li WH, Wang SW, Sun YL, Wang YY, et al. Ehrlichiosis and zoonotic anaplasmosis in suburban areas of Beijing, China. Vector Borne Zoonotic Dis. 2012;12(11):932-7.

23. Ogden NH, Lindsay LR, Hanincova K, Barker IK, Bigras-Poulin M, Charron DF, et al. Role of migratory birds in introduction and range expansion of Ixodes scapularis ticks and of Borrelia burgdorferi and Anaplasma phagocytophilum in Canada. Appl Environ Microbiol. 2008;74(6):1780-90.
Submit your next manuscript to BioMed Central and we will help you at every step:

- We accept pre-submission inquiries

- Our selector tool helps you to find the most relevant journal

- We provide round the clock customer support

- Convenient online submission

- Thorough peer review

- Inclusion in PubMed and all major indexing services

- Maximum visibility for your research

Submit your manuscript at www.biomedcentral.com/submit
) BioMed Central 